\title{
The Resettlement Challenge: Integration of Refugees from Protracted Refugee Situations
}

\author{
Debra Pressé and Jessie Thomson
}

\section{Abstract}

This paper explores Canada's response, through our Refugee and Humanitarian Resettlement Program, to developments in international refugee policy and will ask how Canada's resettlement program could be used more strategically in the future so as to meaningfully contribute to resolving protracted refugee situations globally while ensuring the successful integration of refugees from these situations.

\section{Résumé}

Ce document examine la réponse du Canada à l'évolution de la politique internationale sur les réfugiés, par le biais de son Programme de réinstallation des réfugiés et des personnes protégées à titre humanitaire, et il se demande comment le programme de réinstallation $d u$ Canada pourrait être utilisé de façon plus stratégique dans l'avenir pour contribuer de manière significative à résoudre les situations de réfugiés de longue durée dans le monde, tout en assurant la bonne intégration de ces réfugiés.

\section{Introduction}

Fifteen years have passed since the forcible exile of the majority of the ethnic Nepali southern Bhutanese population without a durable solution for the approximately 106,000 people now living in the refugee camps in southeastern Nepal. ${ }^{1}$

According to the 2006 edition of The State of the World's Refugees by the United Nations High Commissioner for Refugees (UNHCR), of over eight million refugees in the world at that time, some six million were considered to be in a protracted refugee situation. Further, the average duration of displacement has increased from nine years in 1993 to seventeen years in $2003 .^{2}$ In total, UNHCR has identified at least thirty-three major protracted refugee situations around the globe, not counting those outside UNHCR's definition due to their size and scope, which are also longterm situations of displacement. ${ }^{3}$ These important statistics point to the seriousness and scope of protracted refugee situations globally.

It is clear, fifty-six years after the signing of the Refugee Convention relating to the Status of Refugees (Refugee Convention), that the phenomenon of refugee movements persists and that what was once thought to be a short-term challenge is a reality that is often ongoing for decades. More and more refugees find themselves "warehoused"4 in refugee camps for years, without access to a durable solution. Not only are refugees unable to return to their country of origin voluntarily, but, in many of these cases, refugees languish in refugee camps, dependent on humanitarian assistance and food aid, with limited or no opportunities for self-reliance or local integration. Densely populated refugee camps with limited opportunities become the home and community of those who have been forcibly displaced for decades. As a result, a significant portion of today's refugees have severe psychosocial and physical health concerns, limited or no labour market skills, little or no formal education, and, for children, greater developmental challenges. ${ }^{5}$ This in itself can be a disincentive for States hosting large refugee populations to provide for local integration and for other States to engage in resettlement of refugees with high needs.

This paper will outline the emphasis that Canada, the UNHCR, and other countries have placed on protracted 
populations and will examine how this emphasis is the logical extension of policy development undertaken both internationally and domestically since the Global Consultations were launched in 2000. It will also explore how Canada's Refugee and Humanitarian Resettlement Program plays a role in securing durable solutions for refugees and will look to the future, asking questions about how Canada can best address the protracted nature of refugee displacement, while also exploring what this means for how Canada provides integration support to resettled refugees in order to meet their unique needs when coming from a protracted refugee situation.

\section{Refugee Resettlement and the Agenda for Protection}

The international community, led by the UNHCR, views a refugee as having secured a solution to his or her plight if the refugee has been able to find a safe and permanent (durable) solution through one of three means: voluntary repatriation to the country of origin in safety and dignity; local integration $^{6}$ in the country of asylum; or resettlement to a third country.

Over the past fifty years, millions of people have found a durable solution through resettlement. Since the Second World War, more than 860,000 refugees and persons in similar circumstances have been resettled to Canada. ${ }^{7} \mathrm{Un}$ like asylum determination from within Canada, which derives from Canada's legal obligations as a signatory to the Refugee Convention, resettlement of refugees from abroad is a policy decision undertaken as part of our contribution to international burden sharing. In addition to those granted protection through the in-Canada asylum system, each year, under the Refugee and Humanitarian Resettlement Program, Canada resettles from abroad between 10,300 and 12,000 refugees. $^{8}$ Of this number, 7,300 to 7,500 are admitted to Canada under the Government Assisted Refugee (GAR) program while the balance are admitted under the Private Sponsorship of Refugees (PSR) program. ${ }^{9}$ Private sponsors, members of organizations, and faithbased groups in Canada have assisted over 193,000 persons since 1978 through the PSR program.

To respond to new realities in the refugee context, and in part to react to large-scale protracted refugee situations, the UNHCR launched the Global Consultations on International Protection in 2000 in an effort to revitalize the international protection regime. These consultations led to the Agenda for Protection. ${ }^{10}$ The Agenda for Protection serves as a blueprint that sets out enumerated goals and concrete ways states can redouble their efforts to enhance refugee protection and find solutions for more refugees. Resettlement is addressed in goal five of the Agenda for Protection, which calls on States to increase their resettlement numbers, diversify the kinds of refugee groups they welcome, and introduce more flexible resettlement criteria in an effort to secure more durable solutions, particularly for protracted refugee situations. These consultations initiated, inter alia, a discussion on how the international community could use resettlement more strategically in order to benefit more refugees. In 2003, the international community defined a strategic use of resettlement as one where resettlement activity leads to planned direct and indirect benefits accruing to refugees not being resettled. ${ }^{11}$ For example, a strategic use of resettlement can help sustain access to asylum in the face of a continued refugee flow; it can also play a role in providing access to more services for the general refugee population. Ideally, a strategic use of resettlement would also help lead to comprehensive solutions for specific refugee populations involving all three durable solutions. ${ }^{12}$

With this in mind, the international community, led by Canada and UNHCR, drafted and agreed to the Multilateral Framework of Understandings for Resettlement (MFU) in 2004. ${ }^{13}$ This was an important development for advancing the concept of the strategic use of resettlement and in encouraging resettlement countries to pursue resettlement arrangements that would promote and be part of comprehensive solutions to particular refugee situations.

These developments in the international policy context emphasized the fact that resettlement could not operate in isolation from the other durable solutions and emphasized a need for more strategic and coordinated engagement on the part of resettlement countries to ensure they were part of a wider solution to the refugee dilemma. It was acknowledged that beyond the important role that resettlement can play in helping one family or one individual, resettlement, when pursued in a strategic fashion and in line with the MFU, could have wider positive implications. Further, it was widely agreed that resettlement countries could most effectively help to share the burden of refugee hosting countries, by targeting more vulnerable segments of the refugee population in order to alleviate some of the pressure on refugee camps and refugee hosting communities.

Historically, Canada, among other resettlement countries, had been criticized for selecting the "best and the brightest" refugees and thereby exacerbating the situation in the refugee camps where these individuals were selected. As a result, concurrent to and in line with the discussions at the international level, Canadian policies shifted in 1998 and were then formalized in 2002 with the implementation of the Immigration and Refugee Protection Act (IRPA) and Regulations. IRPA institutionalized this effort to focus on refugees' protection needs in part by softening the selection 
criteria used to assess refugees' integration potential and by exempting refugees from certain medical requirements. ${ }^{14}$ In addition to changing eligibility criteria, Canada also shifted the focus of its resettlement program to those most in need of protection.

While Canadian legislation retained a requirement for refugees to be able to demonstrate "an ability to establish" in Canada, it put "protection" first and foremost and "ability to establish" second. Persons found to be in urgent need of protection and those found to be more vulnerable in relation to the general refugee population in which they live are exempt from the need to demonstrate any integration potential. Further, all resettled refugees are exempt from certain medical requirements. In the implementation of IRPA, the "ability to establish" requirement is rarely used as a reason for refusal. Further, in the context of group processing, public policies have been instituted within the framework of the IRPA such that the entire group being considered for resettlement is deemed vulnerable and therefore everyone within the group is exempt from the ability to establish requirement. At the same time, Canada acknowledges the importance of ensuring that those who are resettled make an active and informed choice about resettlement, which at times can mean that some persons among the most vulnerable are more hesitant or unwilling to pursue resettlement.

\section{Canada's Evolving Resettlement Focus}

At the fifty-seventh session of the UNHCR Executive Committee (EXCOM) in October 2006, the Government of Canada called on UNHCR to make resolution of protracted refugee situations a priority in 2006 and beyond. In addition to the humanitarian imperative, Canada has a strategic interest in helping refugees find lasting solutions-because the longer refugee populations languish without access to durable solutions, the greater the risk they could pose to stability in their region, resulting in more refugee outflows. As such, Canada is exploring how its own resettlement program could be better used to help manage down refugee numbers and contribute to the Agenda for Protection.

One way to advance goal five of the Agenda for Protection is by focusing a portion of our resettlement efforts on specific protracted refugee situations. Today, Citizenship and Immigration Canada (CIC) is actively involved with some of the major situations identified by the UNHCR in the 2006 edition of The State of the World's Refugees. ${ }^{15}$

This shift in Canadian policies resulted in a significant change in Canada's resettled refugee population. First, the change has allowed far more persons with higher medical and other settlement requirements, including post-traumatic stress disorder and trauma counselling, to be eligible for resettlement. Second, the refugee pool from which Canada selects has shifted from one primarily consisting of European-based political dissidents to one that is largely African, Middle Eastern, and Asian based. Given that some of these groups come from entirely different political, economic, and social contexts, many refugees now have different settlement needs that include special requirements arising from years of trauma or torture followed by years in camps.

These complex refugee situations have given rise to a need for much greater individualized and, in some cases, specialized attention if we are to help today's refugees integrate and establish themselves successfully in Canada.

\section{Current Integration Challenges}

Successful integration is undefined in both legislation and policy. While there is some consensus on what integration is, there continues to be a debate around what is meant by successful integration and how success can be measured or defined. A useful starting point is found in the UNHCR's Refugee Resettlement: An International Handbook to Guide Reception and Integration (2002).

Integration is a mutual, dynamic, multifaceted and on-going process. From a refugee perspective, integration requires a preparedness to adapt to the lifestyle of the host society without having to lose one's own cultural identity. From the point of view of the host society, it requires a willingness for communities to be welcoming and responsive to refugees and for public institutions to meet the needs of a diverse population.

It is important to note that under the Multilateral Framework of Understandings on Resettlement, countries, including Canada, agreed that prior to resettlement, measures are to be put in place to provide for the appropriate reception and integration of resettled refugees. This is particularly important for Canada as recent research indicates that today's refugees are achieving lower economic outcomes than in the past. CIC recognizes that current resettlement programming may not adequately meet the unique and changing needs of refugees.

This challenge grows partly out of the fact that, despite the policy changes regarding eligibility for resettlement, few changes were made to how refugees, once selected, are supported in their integration process within the Refugee and Humanitarian Resettlement program. For instance, although the change in the refugee profile has created significant pressures for program administrators and those in front-line service delivery, the Resettlement Assistance Program (RAP), which in essence was established to provide 
benefits comparable to those offered by provincial social assistance programs, has not changed since its creation in 1998. ${ }^{16}$ Such social assistance programs, however, are neither necessarily geared to helping refugees coming from diverse backgrounds and extended camp stays adapt to daily life in a North American context nor to addressing their health issues, which vary significantly from our historical experiences with immigrant health issues.

Although there are numerous programs available to facilitate the integration process of newcomers to Canada, these may be difficult to access and are most often not tailored to the particular needs of the resettled refugees, particularly those coming from protracted refugee situations.

\section{Meeting the Integration Challenge}

If Canada is to contribute meaningfully to managing down protracted refugee numbers while serving Canadian interests that include maintaining the public health and security of Canadians and facilitating integration of refugees, then a more strategic focus on individual needs is warranted. For example, the effects of war and trauma on the subsequent integration of refugee children and youth are not well understood. Research suggests that surviving war and its related trauma can have devastating social and psychological consequences for these youth. ${ }^{17}$ Today, over 50 per cent of the world's refugee population consists of children under the age of eighteen. In 2006, 52 per cent of resettled refugees under the Government Assisted Refugee program were under the age of twenty-two. Yet despite these large numbers, little research has been undertaken to help us understand what happens to refugee youth once they are resettled.

In order to better facilitate integration, it is important to understand that integration is in fact a continuum with the starting point well before the refugee arrives in Canada and the end point years after arrival. More recently, settlement workers have posited that a needs-based approach, focused on the individual needs of the client, is required to better assist in the settlement and integration of refugees throughout the resettlement continuum.

One of the major challenges both in the context of measuring success and within efforts to define a more client-centered approach (based on unique needs of individuals and groups) is securing an evidence base for these key areas. This is particularly challenging for refugees, as there is a gap in research exploring "social indicators" of success. Further, much of the research that does exist on immigrant needs and outcomes does not disaggregate data between skilled workers and refugees.
Developing integration measurements for refugees needs to take into account both subjective and objective factors, as well as the experiences of different refugee populations. Within the different refugee populations there are also subgroups such as women, men, children, youth, and the elderly who may have widely different settlement needs. Additionally, each protracted refugee situation is unique and when pursuing multilateral approaches to resolving protracted refugee situations, Canada will need to consider the unique resettlement needs of particular groups in order to establish which barriers to services may need to be addressed and which new supports need to be established.

Certain refugee needs can be predetermined to some extent by analyzing the refugee's background. The refugee's situation prior to being resettled (protected camp situation or other), ethnicity, gender, age, language abilities, health issues, and education are general indicators of their needs. These indicators can help policy makers and program designers prepare integration plans for refugees arriving from protracted refugee situations that include follow-up and monitoring to ensure that the needs of individuals are being met. This has been flagged by a number of reports as being a critical component in integration that is currently lacking in the Canadian system. ${ }^{18}$

Specialized services may also need to be developed to meet the evolving unique needs of refugees. Medical and other needs assessments could help identify what specific resettlement requirements refugees have for which there are currently insufficient programs and services. In turn, these services would need to be developed in communities where refugee populations with those needs have been identified or where community-mapping exercises have indicated that services are currently lacking.

CIC believes the length of time required to negotiate multilateral frameworks for resettlement provides an opportunity to address some of the settlement challenges faced by refugees. For example, it is possible, with more planning, to use the time between developing a comprehensive strategy and actual departure of large numbers of refugees over a multi-year period to develop and implement detailed and population specific pre-departure programs. Such programs, in concert with humanitarian aid that focuses on primary and secondary education, preventative health treatment, skills upgrading, comprehensive cultural orientation, and language training when feasible, could help refugees selected for resettlement more readily make the transition from refugee to citizen. Ideally, initiatives would include members of the general refugee population who are not being resettled as such programs would also improve their own prospects for return (if conditions 
are right) and help host countries sustain asylum space and encourage conditions for local integration.

\section{Conclusion}

The Rohingyas in the camps in Cox's Bazaar are the remainder of a group of ... refugees who fled into Bangladesh in 1992 to escape persecution by the military junta. . . more than 26,000 remain in the camps, afraid to return. An estimated 100,000 to 200,000 also live around Cox's Bazaar, but outside the camps. ${ }^{19}$

Canadians have traditionally responded with generosity to refugee crises and humanitarian emergencies. Protracted refugee situations are emergencies that have been forgotten for too long. Canada, as one of the countries that endorsed the Agenda for Protection, has a role to play in developing concerted strategies to address refugee situations. A Canadian contribution could include substantial efforts to help create and sustain, especially in fragile and post-conflict states, the environments necessary to support effective protection and to establish the conditions for sustainable durable solutions.

In addition, through a more focused resettlement program that targets specific refugee populations that have been warehoused for years on end, Canada can make a tangible positive impact in some refugee situations. The multi-faceted ways in which different variables affect the integration continuum, however, indicate the need for policies and programs that are grounded in current research designed to target specific refugee populations.

More empirical studies of the impacts of protracted refugee situations are needed to guide future engagement of Canada's Refugee and Humanitarian Resettlement Program. Research studies must consider the various natures of refugee situations and address questions such as: are camp-based populations more or less at risk than urban refugee populations? What are the health needs of refugees in camps in Asia versus those in Africa? What are the differences in trauma and torture narratives among the various protracted situations identified by the UNHCR?

The responses to these and other questions would assist Canada in engaging substantively in multilateral frameworks regarding comprehensive solutions and assist in ensuring the successful integration of those refugees resettled in Canada.

\section{Notes}

1. Joint NGO letter, "Nepal/Bhutan: resolve protracted refugee problem," to the delegates of the Bhutan Donors Round Table meeting, 9 February 2006, online: South Asian Media Net, 10 February 2006, <http://www.southasianmedia.net/index_
opinion.cfm?category=Human\%20Rights\&country=Bhutan> (accessed January 10, 2007).

2. The UNHCR defines a protracted refugee situation as "one in which refugees find themselves in a long-lasting and intractable state of limbo. Their lives may not be at risk, but their basic rights and essential economic, social and psychological needs remain unfulfilled after years in exile. A refugee in this situation is often unable to break free from enforced reliance on external assistance." The UNHCR currently uses a "crude measure of refugee populations of 25,000 persons or more who have been in exile for five or more years in developing countries" to effectively define protracted refugee situations. Protracted situations may include both camp-based and urban-refugee populations. United Nations High Commissioner for Refugees, Protracted Refugee Situations (June 2004), $<$ http://www.unhcr.org/excom/EXCOM/40c982172.pdf >.

3. Gil Loescher and James Milner, "Protracted Refugee Situations: The Search for Practical Solutions," in The State of the World's Refugees 2006: Human Displacement in the NewMmillennium, ed. N. Merheb (Oxford: Oxford University Press, 2006).

4. US Committee for Refugees first applied the term "warehousing"to refugees in its World Refugee Survey in 2004.

5. See UNHCR, Refugee Resettlement: An International Handbook to Guide Reception and Integration (Geneva: UNHCR, 2002) for examples of the types of special needs refugees may have as a result of prolonged exile. It is estimated that around one in three of the world's refugees has had at least one experience of torture. Studies of refugees offered permanent resettlement indicate that one in four has been subject to torture or severe human rights violations, with almost seven in ten being subject to other traumatic events such as prolonged political repression and the loss of family members in violent circumstances.

6. Commonly referred to as one of the three durable solutions available to refugees, "local integration is based on the assumption that refugees will remain in their country of asylum permanently and find a solution to their plight in that State. It is a legal, economic and socio-cultural process whereby refugees are granted a progressively wider range of rights and entitlements by the host State that are broadly commensurate with those enjoyed by its citizens. These include freedom of movement, access to education and the labour market, access to public relief and assistance, including health facilities, the possibility of acquiring and disposing of property, and the capacity to travel with valid travel and identity documents. Realization of family unity is another important aspect of local integration." UNHCR, Resettlement Handbook, rev. edn. (Geneva: UNHCR, 2004).

7. This figure includes privately sponsored refugees and the dependants of persons granted asylum in Canada where the dependant was residing abroad when the principal applicant received protection in Canada. The total number also includes preliminary 2006 figures. 
8. Canada establishes "targets" every year, which means our goal is to resettle at least 10,300 refugees and up to 12,000 . The upper end of the target for 2007 was increased from 11,500 to 12,000 .

9. Government Assisted Refugees are normally refugees who are referred to Canada by the UNHCR and supported through Canada's Resettlement Assistance Program during their first year in Canada if living outside Quebec. Quebec supports refugees destined to that province under the terms of the Canada-Québec Accord. Private sponsors refer most Privately Sponsored Refugees to CIC. Private sponsors provide resettled refugees with lodging, care, and settlement assistance for the first year. In exceptional cases, refugees are supported for two to three years.

10. For the full text of the Agenda for Protection, see UNHCR, Agenda for Protection, $3^{\text {rd }}$ ed. (October 2003), 5-7; 73-81, $<$ http://www.unhcr.org/protect/PROTECTION/3e637b194. pdf> (accessed December 8, 2006).

11. UNHCR, Discussion Paper on the Strategic Use of Resettlement by the Working Group on Resettlement (June 2003), <http:// www.unhcr.org/protect/PROTECTION/3ee6dc6f4.pdf $>$.

12. A comprehensive solution is one where concerted effort by a wide range of actors to address a particular refugee crisis results in the vast majority of individuals within a refugee population finding a durable solution through repatriation, local integration, or resettlement. The international response to the Indochinese refugee crisis in Southeast Asia is an important example of a comprehensive solution.

13. A core group led by Canada negotiated the MFU. This group consisted of States from both the developed and developing world, including States hosting refugees for protracted periods, as well as long-standing and emerging resettlement countries, namely: Canada, Australia, Brazil, Denmark, Ecuador, Egypt, the Islamic Republic of Iran, Kenya, Nepal, the Netherlands, Nigeria, South Africa, Sweden, the United Republic of Tanzania, Thailand, the United Kingdom, and the United States of America. The European Commission and the International Organization for Migration (IOM) were also members of the group. See <http://www.unhcr.org/protect/PROTECTION 414aa7e54.pdf $>$.

14. Prior to the implementation of the Immigration and Refugee Act and Regulations in 2002, refugees from abroad were selected in part based on their individual ability to communicate in an official language, work and educational experience and potential to successfully integrate within a one-year period.
Current legislation emphasizes the refugee's protection needs over his or her ability to establish. In addition, the refugee's integration potential is assessed against the backdrop of his or her entire family's available supports and how well they can be expected to establish within three to five years instead of the previous one year time frame.

15. Canada is actively resettling Somali and Sudanese in Kenya, Afghans in Pakistan, and Karen from Burma (also known as Myanmar) out of Thailand. In addition, Canada has been approached to participate in a multilateral resettlement program of Eritreans out of Sudan. Further, while not listed among the thirty-three major protracted refugee situations, Canada has indicated interest in resettling Chin out of Malaysia. Canada is also involved in multilateral negotiations pursuing comprehensive solutions to the long-standing situations of Bhutanese refugees in Nepal and Rohingya in Bangladesh.

16. All refugees admitted to Canada under the resettlement program are also able to access emergency medical and dental treatment under the Interim Federal Health (IFH) program as well as foundational integration programs such as Language Instruction for Newcomers to Canada (LINC), HOST, and other services provided through the Integration and Settlement Adaptation Program.

17. Lori Wilkinson, "Factors Influencing the Academic Success of Refugee Youth in Canada," Journal of Youth Studies 5, no. 2 (2006): 173-193.

18. Usha George, "A Needs-Based Model for Settlement Service Delivery for Newcomers to Canada," International Social Work 45, No. 4 (2002), <http://isw.sagepub.com/cgi/content/abstract/ $45 / 4 / 465>$.

19. UNHCR, Briefing Notes (15 December 2006), <http://www. unhcr.org/news/NEWS/45827c8a20.html>.

Debra Pressé and Jessie Thomson are employed in the Refugees Branch of Citizenship and Immigration Canada. Jessie is currently on secondment as a Senior Policy Advisor in the Humanitarian Affairs and Disaster Response Group at the Department of Foreign Affairs and International Trade. The views expressed in this paper are those of the authors and do not necessarily reflect the official views of Citizenship and Immigration Canada. 